\title{
Atopic Dermatitis Progression: Evaluating Intervention Strategies
}

\author{
Linda F. Stein Gold, MD,* and Lawrence F. Eichenfield, $\mathrm{MD}^{\dagger}$
}

\section{Abstract}

Several risk factors have been identified that appear to be consistently and strongly associated with the development of atopic dermatitis (AD): a family history of atopy, an inherited genetic predisposition, and active and passive exposure to tobacco smoke. Recent studies also have demonstrated that a simple intervention from birth-the daily application of an emollient moisturizer-seems to protect susceptible infants from the development of AD.

Semin Cutan Med Surg 36(supp2):S39-S41

(C) 2017 published by Frontline Medical Communications

\section{Keywords}

Atopic dermatitis; eczema; emollients; filaggrin; food allergy; inflammatory cytokines; interleukin; T helper cells

A fundamental question concerning atopic dermatitis (AD) has been the topic of many recent studies: What are the relative contributions of genetics and environment in disease susceptibility and expression?

\section{Genetic Predisposition and Family History}

Evidence for a genetic predisposition in AD comes from a variety of studies. Most recently, a study comparing AD in identical and fraternal twins demonstrated concordance rates of up to 0.86 in monozygotic and 0.41 in dizygotic pairs, providing clear evidence for a genetic predisposition to AD. ${ }^{1}$

In addition, Wen and colleagues ${ }^{2}$ reported that about $70 \%$ of patients with AD have a positive family history for atopic diseases. Previous studies had demonstrated that the chances of a patient having $\mathrm{AD}$ are 2- to 3-fold if one parent has $\mathrm{AD}$,

\footnotetext{
*Director of Dermatology Research, Henry Ford Health System,

Detroit, Michigan

†Chief, Pediatric and Adolescent Dermatology, Professor of Dermatology and Pediatrics, Rady Children's Hospital, University of California, San Diego School of Medicine, San Diego, California
}

Publication of this CME/CE article was jointly provided by University of Louisville, Postgraduate Institute for Medicine, and Global Academy for Medical Education, LLC, and is supported by an educational grant from Anacor Pharmaceuticals, Inc. The authors have received an honorarium for their participation in this activity. They acknowledge the editorial assistance of Joanne Still, medical writer, and Global Academy for Medical Education in the development of this continuing medical education journal article.

Linda F. Stein Gold, MD, Consultant: Anacor. Grant/Research: Anacor, GlaxoSmithKline. Data Monitoring Committee: Otsuka America Pharmaceutical, Inc.

Lawrence F. Eichenfield, MD, Advisory Board/Speaker: Valeant Pharmaceuticals North America LLC. Consultant: Anacor/Pfizer Inc., Eli Lilly and Company, Genentech, Inc., Otsuka/Medimetriks Pharmaceuticals, Inc., Sanofi Genzyme/Regeneron Pharmaceuticals, TopMD, Valeant. Investigator: Sanofi Genzyme/Regeneron.

Address reprint requests to: Linda F. Stein Gold, MD, 2360 Heronwood Drive, Bloomfield Hills, MI 48302; 1stein1@hfhs.org

1085-5629/13/\$-see front matter (C) 2017 Frontline Medical Communications doi:10.12788/j.sder.2017.010 and 3- to 5-fold if both parents are atopic. ${ }^{3,4}$ Interestingly, Ruiz and colleagues ${ }^{5}$ demonstrated more than 2 decades ago that a maternal history of $\mathrm{AD}$ may be more predictive than a paternal history.

\section{Exposure to Tobacco Smoke}

A meta-analysis across 86 studies showed that both active and passive exposure to tobacco smoke increases AD risk, with an odds ratio of $1.87 .{ }^{6}$

\section{Role of the Filaggrin Gene}

The role of the filaggrin gene in the development of AD has become widely recognized within the past decade. In 2006, Irvine and McLean ${ }^{7}$ studied the histology of normal and atopic skin and demonstrated that the skin in AD has a defective barrier, with an absence of filaggrin-containing keratohyalin granules in the epidermal granular layer. These granules are known to be crucial to the formation of a tight, functional skin barrier.

Research regarding the nature and role of filaggrin has demonstrated that filaggrin is formed when profilaggrinwhich is encoded by the filaggrin gene $(F L G)$ - degrades. Later, as filaggrin itself breaks down, the resulting products contribute to the formation of natural moisturizing factor, which is important for epidermal hydration and barrier function. The absence of the filaggrin gene (ie, an FLG null mutation) is associated with a risk for the earlier onset of $\mathrm{AD}$, as well as for more severe and persistent disease. Patients with an FLG null mutation have 1.2 to 13 times the risk for the development of $\mathrm{AD}{ }^{8}$

Although FLG mutations have been noted in patients with $\mathrm{AD}$ from various ethnic and geographic populations, demonstrating its importance in the pathogenesis of $\mathrm{AD}$, some questions remain to be explored. For example, a substantial number of patients who have AD have no identifiable $F L G$ mutations, whereas approximately $40 \%$ of individuals with $F L G$ null alleles do not develop AD. ${ }^{8}$

Such questions raise the possibility that a filaggrin abnormality might develop, de novo, in patients who have no evidence of an inherited FLG mutation. Howell and colleagues $^{9}$ explored this question in a study designed to determine whether $F L G$ expression could be reduced in patients who had AD but were not carriers of any identified FLG mutations. These investigators enrolled 39 patients with no history of $\mathrm{AD}$ and 30 patients with moderate $\mathrm{AD}$. Among their other findings, the researchers detected the presence of interleukin (IL)-4 and IL-13 in patients with AD; in these patients, keratinocytes showed significantly reduced filaggrin expression. They concluded that the patients with AD in this study had an acquired defect in filaggrin expression in the presence of an atopic inflammatory response. 


\section{AD Immunology}

$\mathrm{AD}$ is an immunologic disorder characterized by $\mathrm{T}$ helper cell dysregulation, mast cell (basophil and eosinophil) hyperactivity, and immunoglobulin $\mathrm{E}$ (IgE) production; the latter may be a factor that occurs secondary to other events. In addition, AD is associated with an imbalance in T-cell subsets, with type $2 \mathrm{~T}$ helper $\left(\mathrm{T}_{\mathrm{H}} 2\right)$ cells predominating. The key $\mathrm{T}_{\mathrm{H}} 2$ cytokines include IL-4, IL-5, and IL-13. In addition, a specific cytokine, IL-31, has been identified, informally referred to as the "pruritus-specific" cytokine.

\section{Modulating Barrier Dysfunction in AD}

Identification of the role of skin barrier dysfunction in patients with $\mathrm{AD}$ and extensive study of the underlying disease immunology has allowed investigators to explore the possibility of (1) identifying susceptible patients early in life and (2) preventing or minimizing the risk for the development of AD. Recent studies have demonstrated that both of these goals are achievable in many, if not all, patients with AD.

In a study of 1,903 newborns, Kelleher and colleagues ${ }^{10}$ evaluated skin barrier function at birth (on day 2) and at 2 and 6 months of age by assessing transepidermal water loss (TEWL) (so-called "leaky skin"). In addition, 1,300 infants were tested for the presence of FLG mutations. The investigators reported that $18.7 \%$ of the babies were diagnosed with $\mathrm{AD}$ at 6 months of age; at 12 months of age, $15.53 \%$ had AD. The upper quartile of TEWL measurement at day 2 was "significantly predictive" of an AD diagnosis at 12 months of age $(P<0.05)$. Conversely, the lowest quartile of TEWL at day 2 was associated with protection against $\mathrm{AD}$ at 12 months of age. In addition, the upper quartile of TEWL measurement at 2 months of age also was significantly predictive of $\mathrm{AD}$ at 12 months $(P<0.05)$. Parental AD history and infant $F L G$ status were not factors in these results.

To explore the potential protective effects of minimizing TEWL, Simpson and colleagues ${ }^{11}$ enrolled infants at increased risk for AD in a preliminary study of emollient use. The Barrier Enhancement for Eczema Prevention (BEEP) study was designed to determine whether parents would be willing to have their newborns randomized to receive either no emollients (the control group) or full-body applications of topical emollients at least once daily, beginning at 3 weeks of age (intervention group). The investigators reported that $42 \%$ of families agreed to the randomization. The primary endpoint was to establish whether emollient application was a feasible strategy. In addition, data were collected on the development of $\mathrm{AD}$ at 6 months of age in the intervention and control groups.

The authors reported that emollient use had a statistically significant protective effect, with a relative reduction in the risk of $\mathrm{AD}$ of $50 \%$ (relative risk, $0.50 ; 95 \% \mathrm{CI}, 0.28-0.9 ; P=0.017$ ). No emollient-related adverse effects were reported, and no differences in adverse effects were seen between the intervention and control groups. Although this study was small and was not designed to establish efficacy and safety, the results suggest that larger, randomized controlled trials are warranted.

Meanwhile, other small studies have yielded similar findings regarding the protective effects of emollient use in infants, including a study of 136 subjects from Great Britain ${ }^{12}$ and a study from Japan involving 118 subjects. ${ }^{13}$

\section{Predicting Long-Term AD Persistence}

Clinicians know from experience that $\mathrm{AD}$ resolves over time in most children, with few having persistent AD into adulthood. However, predicting which individuals will have persistent disease has not been possible. In a recently published metaanalysis of 45 studies from 15 countries (involving 110,651 patients, for a total of 434,992 patient-years), Kim and colleagues ${ }^{14}$ found that three main factors were involved in the risk for persistence of $\mathrm{AD}$ into adulthood: (1) disease in childhood that persists for 10 years or more (compared to $\leq 5$ years); (2) onset of AD later than 2 years of age; and (3) greater vs less severity of AD in childhood.

\section{Role of Food Allergies in AD}

Because some patients with mild to moderate AD also have food allergies, many parents (and some clinicians) assume that a causative relationship exists. Although older studies estimated an $\mathrm{AD} /$ food allergy comorbidity incidence for mild to moderate $\mathrm{AD}$ of $30 \%$ to $40 \%$, more recent evidence shows that the incidence actually is about $15 \%$ in this subpopulation of patients ${ }^{15}$; the incidence of food allergy among patients with severe AD is approximately $35 \% .{ }^{16}$ Interestingly, a review and meta-analysis of prospective studies shows that breastfeeding may decrease the incidence of AD. ${ }^{17}$

The strategy of blindly eliminating commonly allergenic foods - including cow's milk, eggs, and peanuts-from the diets of all patients with AD is not effective in modifying the course of AD. Nevertheless, food and other allergies may contribute to $\mathrm{AD}$ in some patients. Consider referring patients to a pediatric allergist for evaluation when $\mathrm{AD}$ is moderate to severe, when skin disease is recalcitrant, and in the presence of a reliable history of exacerbation after exposure to certain foods. Teenagers or adults with severe AD also may benefit from an allergy evaluation.

Recent work by $\mathrm{Du}$ Toit and colleagues ${ }^{18}$ has demonstrated that exposure to foods actually may protect children from food allergies. This study, Learning Early About Peanut Allergy (LEAP), was a randomized controlled trial of early exposure to peanuts of children at high risk for developing a food allergy. The study population in LEAP consisted of 640 infants between 4 and 11 months of age with severe eczema, egg allergy, or both. All subjects received a skin-prick test to determine sensitivity to peanuts. All patients with a negative skin-prick test were randomized to either consume or avoid peanuts. Among children with positive skin-prick tests, children with wheals of $5 \mathrm{~mm}$ or larger were excluded from the study; children with wheals of 1 to $4 \mathrm{~mm}$ were randomly assigned to either consume or avoid peanuts.

At 60 months of age, the children were tested for peanut allergy by oral challenge. Among the children with initially negative skin-prick tests, the prevalence of peanut allergy was $13.7 \%$ in the avoidance group and $1.9 \%$ in the consumption group, a statistically significant difference $(P<0.001)$. Among the enrolled patients with an initially positive skin-prick test, the prevalence of peanut allergy was $35.3 \%$ in the avoidance group and $10.6 \%$ in the consumption group $(P=0.004)$.

The results of this and other studies has led to a revision in guidelines for feeding and allergy testing in children with severe $\mathrm{AD}$ in the first year of life, calling for skin-prick testing or IgE screening to determine whether a child should have early peanut feeding. Dermatologists and pediatricians should collaborate with an allergist in managing the care of these patients. 


\section{Conclusion}

Atopic dermatitis is a common relapsing inflammatory condition with genetic as well as environmental risk factors. New research has contributed to a better understanding of this disease and improved strategies for prevention and treatment.

\section{References}

1. Elmose C, Thomsen SF. Twin studies of atopic dermatitis: Interpretations and applications in the filaggrin era. J Allergy (Cairo). 2015;2015:902359.

2. Wen HJ, Chen PC, Chiang TL, Lin SJ, Chuang YL, Guo YL. Predicting risk for early infantile atopic dermatitis by hereditary and environmental factors. $\mathrm{Br} J$ Dermatol. 2009;161:1166-1172.

3. Wadonda-Kabondo N, Sterne JA, Golding J, et al. Association of parental eczema, hayfever, and asthma with atopic dermatitis in infancy: Birth cohort study. Arch Dis Child. 2004;89:917-921.

4. Küster W, Petersen M, Christophers E, Goos M, Sterry W. A family study of atopic dermatitis. Clinical and genetic characteristics of 188 patients and 2,151 family members. Arch Dermatol Res. 1990;282:98-102.

5. Ruiz RG, Kemeny DM, Price JF. Higher risk of infantile atopic dermatitis from maternal atopy than from paternal atopy. Clin Exp Allergy. 1992;22:762-766.

6. Kantor R, Kim A, Thyssen JP, Silverberg JI. Association of atopic dermatitis with smoking: A systematic review and meta-analysis. J Am Acad Dermatol. 2016;75:1119-1125.e1.

7. Irvine AD, McLean WHI. Breaking the (un)sound barrier: Filaggrin is a major gene for atopic dermatitis. J Invest Dermatol. 2006;126:1200-1202.

8. Eichenfield LF, Tom WL, Chamlin SL, et al. Guidelines of care for the management of atopic dermatitis: Section 1. Diagnosis and assessment of atopic dermatitis. J Am Acad Dermatol. 2014;70:338-351.

9. Howell MD, Kim BE, Gao P, et al. Cytokine modulation of atopic dermatitis filaggrin skin expression. J Allergy Clin Immunol. 2009;124(3 suppl 2):R7-R12.

10. Kelleher M, Dunn-Galvin A, Hourihane JO, et al. Skin barrier dysfunction measured by transepidermal water loss at 2 days and 2 months predates and predicts atopic dermatitis at 1 year. J Allergy Clin Immunol. 2015;135:930-935.e1.

11. Simpson EL, Chalmers JR, Hanifin JM, et al. Emollient enhancement of the skin barrier from birth offers effective atopic dermatitis prevention. $J$ Allergy Clin Immunol. 2014;134:818-823.

12. Mason JM, Carr J, Buckley C, et al. Improved emollient use reduces atopic eczema symptoms and is cost neutral in infants: Before-and-after evaluation of a multifaceted educational support programme. BMC Dermatol. 2013;13:7.

13. Horimukai K, Morita K, Narita M, et al. Application of moisturizer to neonates prevents development of atopic dermatitis. J Allergy Clin Immunol. 2014;134: 824-830.e6.

14. Kim JP, Chao LX, Simpson EL, Silverberg JI. Persistence of atopic dermatitis (AD): A systematic review and meta-analysis. J Am Acad Dermatol. 2016;75:681687.e11.

15. Spergel JM, Boguniewicz M, Schneider L, Hanifin JM, Paller AS, Eichenfield LF. Food allergy in infants with atopic dermatitis: Limitations of food-specific IgE measurements. Pediatrics. 2015;136:e1530-e1538.

16. Tsakok T, Marrs T, Mohsin M, et al. Does atopic dermatitis cause food allergy? A systematic review. J Allergy Clin Immunol. 2016;137:1071-1078.

17. Gdalevich M, Mimouni D, David M, Mimouni M. Breast-feeding and the onset of atopic dermatitis in childhood: A systematic review and meta-analysis of prospective studies. J Am Acad Dermatol. 2001;45:520-527.

18. Du Toit G, Roberts G, Sayre PH, et al. Randomized trial of peanut consumption in infants at risk for peanut allergy. $N$ Engl J Med. 2015;372:803-813. 